\title{
Development of life satisfaction in young physicians \\ Results of the prospective SwissMedCareer Study
}

\section{Journal Article}

Author(s):

Klaghofer, Richard; Stamm, Martina; Buddeberg, Claus; Bauer, Georg; Hämmig, Oliver; Knecht, Michaela; Buddeberg-Fischer, Barbara

Publication date:

2011-02

Permanent link:

https://doi.org/10.3929/ethz-b-000159243

Rights / license:

In Copyright - Non-Commercial Use Permitted

Originally published in:

International Archives of Occupational and Environmental Health 84(2), https://doi.org/10.1007/s00420-010-0553-z 


\title{
Development of life satisfaction in young physicians: results of the prospective SwissMedCareer Study
}

\author{
Richard Klaghofer • Martina Stamm • \\ Claus Buddeberg • Georg Bauer • Oliver Hämmig • \\ Michaela Knecht • Barbara Buddeberg-Fischer
}

Received: 9 December 2009/Accepted: 26 May 2010/Published online: 12 June 2010

(C) Springer-Verlag 2010

\begin{abstract}
Purpose The objectives of the study were to investigate the gender-related development of life satisfaction in young physicians over an 8-year period of residency, to compare it with a representative sample, and to analyze the relationships between both person- and health-related factors and life satisfaction.

Methods A prospective study was carried out including five measurement points among a cohort of 337 Swiss physicians. Measurements include domain-specific life satisfaction $\left(\mathrm{FLZ}^{\mathrm{M}}\right)$, sense of coherence (SOC-13), anxiety and depression (HADS-D), chronic stress (TICS) and socio-demographic variables. Data were analyzed with multivariate procedures.

Results Life satisfaction in physicians of both genders is lower compared to a representative sample. Over the 8-year period of residency, the course of life satisfaction seems to be rather unstable and domain-specific. Female physicians are more satisfied with life than their male counterparts. Depressive symptoms and stress experience are highly negatively associated with life satisfaction in multivariate analysis.

Conclusions To study the development of life satisfaction over time, it is more appropriate to use a domain-specific
\end{abstract}

R. Klaghofer $(\bowtie) \cdot$ M. Stamm · C. Buddeberg ·

B. Buddeberg-Fischer

Department of Psychosocial Medicine,

Zurich University Hospital, Haldenbachstrasse 18,

8091 Zürich, Switzerland

e-mail: richard.klaghofer@usz.ch

G. Bauer · O. Hämmig · M. Knecht

Division of Public and Organizational Health, Institute of Social and Preventive Medicine, Zurich University, 8001 Zürich, Switzerland life satisfaction questionnaire than a total score. Furthermore, it is a matter of concern that-compared to a representative sample-physicians in residency show lower life satisfaction at all measurement points. Depressive symptoms and chronic stress are found to diminish life satisfaction. This could keep some physicians from staying in the medical profession. Senior physicians should be aware of the negative impact of chronic stress on life satisfaction.

Keywords Life satisfaction - Depressive symptoms . Stress $\cdot$ Physicians $\cdot$ Prospective study

\section{Introduction}

Job satisfaction and life satisfaction in the medical community have been important issues in the last years (Buddeberg-Fischer et al. 2005, 2008b; Edwards et al. 2002; Jurkat and Reimer 2001; Jurkat 2008; Shanafelt et al. 2003). Most studies on this topic are cross-sectional. Only few studies report on physicians' levels of life satisfaction prospectively (Nylenna et al. 2005) and compare the data with those of the general population (Kjeldstadli et al. 2006; Tyssen et al. 2009). Gender-related differences in the physicians' assessment of life satisfaction are reported controversially. Jurkat (2008) found higher life satisfaction values in female doctors, while other studies did not (Buddeberg-Fischer et al. 2008b; Rockenbauch et al. 2006). Using domain-specific life satisfaction instruments, gender differences are seen, especially in the domains family, leisure activities, and income (Daig et al. 2009). Several studies report that anxiety and depression are related to life satisfaction (Buddeberg-Fischer et al. 2005, 2008a, b; Daig et al. 2009; Tyssen et al. 2009). 
Dissatisfaction among doctors may be caused by the decreased appreciation of the medical profession by the society in the last years (Buddeberg-Fischer et al. 2006); furthermore, physicians experience less autonomy in practising medicine (Edwards et al. 2002) and complain about their low income compared to the workload and compared to other academics (Buddeberg-Fischer et al. 2006). Wellbeing and life satisfaction among doctors is known to ensure good patient care and is an important issue to keep doctors in patient care (Williams E et al. 2007; Williams ES et al. 2007).

The terms 'quality of life,' 'life satisfaction,' and 'wellbeing' are often not clearly differentiated and used synonymously. 'Quality of life' is defined as a multidimensional measure of the congruence between conditions of a certain objective life standard and the subjective assessment of the respective population (Schumacher et al. 2003). The construct 'life satisfaction' is part of the perceived quality of life and an important component of well-being (Rockenbauch et al. 2006). From a conceptual perspective, life satisfaction is characterized as a subjective, cognitive appraisal of one's own conditions regarding different life domains. It is a process in which individuals assess the quality of their lives by their own standards, reflecting the difference between individuals' hopes, expectations, and desires and what individuals consider their current state (Daig et al. 2009). Satisfaction with life can be assessed globally or domain specifically. To date, there is a lack of longitudinal studies on domain-specific life satisfaction. In our prospective SwissMedCareer Study (Buddeberg-Fischer et al. 2010), we investigated the development of life satisfaction domain specifically in a cohort of young doctors over an 8 year time period using the Life Satisfaction Questionnaire $\left(\mathrm{FLZ}^{\mathrm{M}}\right)$ by Henrich and Herschbach (2000).

The objectives of this study are: What are the internal consistency and the retest-reliability of the life satisfaction questionnaire $\left(\mathrm{FLZ}^{\mathrm{M}}\right)$ ? What are the differences in life satisfaction between young physicians and the normal ageadapted community sample? How does the life satisfaction of young physicians develop over an 8-year postgraduate training period; are there gender-related differences? What are the relationships between person- and health-related factors on the one hand and the life satisfaction on the other?

\section{Method}

Study design and study sample

The present study is part of an ongoing prospective survey of a cohort of graduates of the three medical schools in German-speaking Switzerland (SwissMedCareer Study,
Buddeberg-Fischer et al. 2010), beginning in 2001 (T1). All of the 1,004 registered final-year students were sent a letter explaining the study design, accompanied by a recommendation letter of the deans of the three medical schools, and the baseline questionnaire; the students' addresses were provided by the university boards. To ensure participants' anonymity, the returned questionnaires were only identified by a code. The respondents sent their addresses to an independent address-administration office, allowing for follow-up. The study protocol was approved by the ethical committee of Zurich University.

In the first assessment ( $\mathrm{T} 1$, in 2001), 711 graduates participated (Buddeberg-Fischer et al. 2003). Subjects were reevaluated every 2 years. The present paper refers to results of all five assessments; the last assessment was conducted in 2009, 8 years after the participants' graduation (Buddeberg-Fischer et al. 2010).

The study sample consists of 337 physicians (184 women, $54.6 \%$; 153 men, $45.4 \%$ ) participating with a full data set in each FLZ $^{\mathrm{M}}$-module at all 5 measurement points (Response rate $=47.4 \%(n=337$ from $n=711$ at first measurement)). The mean age of the participants at T5 is 35.2 (SD 2.1 years, range 32-49 years). Of the residents, $289(85.8 \%)$ live in a stable partnership, of whom 174 are married. Sixty-eight (37.0\%) of the women and $62(40.5 \%)$ of the men have children.

The participants who did not provide a full $\mathrm{FLZ}^{\mathrm{M}}$ data set (missing data from $\mathrm{T} 2$ to T5) did not differ from the study sample in terms of gender $(p=.33)$, age $(p=.31)$ and total life satisfaction score $(p=.30)$ at T1.

\section{Measurements}

\section{Life satisfaction $\left(F L Z^{M}\right)$}

The FLZ ${ }^{\mathrm{M}}$ was chosen because it is a domain-specific questionnaire. According to Daig et al. (2009), the FLZ ${ }^{\mathrm{M}}$ assesses 'General Life Satisfaction' during the past 4 weeks. It focuses on the subjective satisfaction in eight general aspects of life: 'friends/acquaintances,' 'leisure activities/hobbies,' 'health,' 'income/financial security,' 'occupation/work,' 'housing/living conditions,' 'family life/children,' and 'partner relationship/sexuality.' The respondent is asked to rate his/her satisfaction in a given life domain on a five-point scale from 'dissatisfied' to 'very satisfied' e.g., 'How satisfied are you with your income?'. Giving all persons the possibility to answer all domains, the instruction in the $\mathrm{FLZ}^{\mathrm{M}}$ is 'Please answer all questions, also those which do not apparently apply to you: For instance, if you have no partner, please indicate how content you are with your actual situation (without partner).' The sum of eight life domains is the total life satisfaction, and ranges from 8 to 40 . A representative survey of the 
German population with 5,036 participants ( $53.6 \%$ female) was conducted in 2006 (Daig et al. 2009). Mean age was $48.4(\mathrm{SD}=18.0), 59.9 \%$ were living with a partner, $86.8 \%$ were living in urban area, and $5.8 \%$ were unemployed/ short time work. The characteristics of the study sample closely match those of the total German population. The reliability in this representative community sample is good with Cronbach's $\alpha=.80$ (eight items). As reference sample for our study, we used the subsample of 30-60-year-old men $(n=1,161)$ and women $(n=1,404)$ (Table 2).

In the original version, importance and satisfaction in the mentioned eight life domains are assessed (Henrich and Herschbach 2000). However, FLZ ${ }^{\mathrm{M}}$ scores are often distributed in the medium sections of the scale as a result of the scoring procedure, i.e., only a combination of both, high subjective importance and high subjective satisfaction, leads to high scores (Goldbeck and Schmitz 2001). To avoid this kind of distortion, we only used the satisfaction score and did not weight the satisfaction score by the importance of the specific domain. This procedure is reported by Daig et al. (2009).

Hospital Anxiety and Depression Scale-German Version HADS-D (Herrmann et al. 1995) is a frequently used screening instrument for anxiety and depression with two continuous scales ranging from 0 to 21 . It contains 14 items on a four-point response scale, summed up to separate scores on anxiety ( 7 items) and depression ( 7 items); scale scores $<8$ are in the normal range, $8-10$ indicate possible psychiatric morbidity, and $>10$ probable mood disorder. The HADS-D is validated in general population (Hinz and Schwarz 2001).

The Trier Inventory for the Assessment of Chronic Stress (TICS) (Schulz et al. 2004) measures overall chronic stress by means of a five-point Likert scale ranging from 0 to 4 (never-very often). Twelve items constitute the Screening Subscale of Chronic Stress (TICS-SSCS) used in this study. TICS screening items refer to aspects such as being afraid, that something unpleasant may happen, not being able to suppress worrying thoughts, or not being able to cope with all duties. The TICS-SSCS is a sum score of the 12 items and linearly transformed into standard $\mathrm{T}$-values (mean $=50$, $\mathrm{SD}=10)$. Higher values indicate greater stress.

Sense of Coherence Scale (SOC-13) (Antonovsky 1987) consists of thirteen items (seven-point Likert scale) and measures a person's resistance to stress and his/her ability to manage stress.

The survey questionnaire also included questions on gender, age, partnership, children, and employment in percent.

\section{Statistical analysis}

All analyses were carried out with SPSS Version 15.0 for Windows. Descriptive statistics are given in terms of means and standard deviations, counts and percentages, respectively. Retest-reliability $r(\mathrm{tt})$ was computed with Pearson correlations; Cronbach's $\alpha$ were calculated for internal consistency. Comparisons with the representative community sample in satisfaction with life were conducted with $z$-tests. We used MANOVA for repeated measurements, followed by repeated contrasts to estimate the effects of gender and time (independent variables) and their interactions on the eight domains in satisfaction with life as well as FLZ $^{\mathrm{M}}$ total score (dependent variables). Since all Mauchly's tests were significant $(p \leq .05)$, sphericity could not be assumed. Therefore, we corrected the effects according to Greenhouse-Geisser and reported $F$-statistics and partial $\eta^{2}$. A hierarchical multiple regression analysis was carried out to analyze the relationships between person- and workplace-related factors on the one hand and the life satisfaction on the other: In a first step, we included the socio-demographic variables gender, living in partnership, having own children, and employment in percent in the regression model. In a second step, we additionally included the variables anxiety and depressive symptoms, chronic stress, and sense of coherence, controlled for the mentioned socio-demographic variables. Beta-weights and their standard errors, $t$-statistics, adjusted $R^{2}, F$-statistics, and change in $R^{2}$ and $F$ are reported.

\section{Results}

Reliability of FLZ ${ }^{\mathrm{M}}$

The retest-reliability [stability $r(\mathrm{tt})$ ] and the internal consistency are shown in Table 1 . The stability over the five measurement points amounts from .42 to .61. Cronbach's $\alpha$ achieves satisfactory values with approximately .70 .

Comparison of life satisfaction between physicians and representative community sample

The FLZ ${ }^{\mathrm{M}}$ total scores of life satisfaction in physicians are significantly lower (all $p<.01$ ) in both genders at all measurement points except in men at T3 $(p=.142)$ (see

Table 1 Retest reliability $r(\mathrm{tt})$ of the FLZ ${ }^{\mathrm{M}}$ total score and internal consistency (Cronbach's $\alpha)$ of the FLZ ${ }^{\mathrm{M}}(N=337)$

\begin{tabular}{lccccl}
\hline FLZ ${ }^{\mathrm{M}}$ total score & T2 & T3 & T4 & T5 & Cronbach's $\alpha$ \\
\hline T1 & .46 & .43 & .42 & .48 & .65 \\
T2 & & .51 & .49 & .43 & .70 \\
T3 & & & .61 & .54 & .69 \\
T4 & & & & .51 & .70 \\
T5 & & & & & .70 \\
\hline
\end{tabular}


Table 2) compared to a representative community sample. The significant differences between the study sample and the representative community sample in the $F L Z^{\mathrm{M}}$ total scores result mainly from the significantly lower satisfaction with leisure activities (all $p<.001$ ) in young physicians and also from the lower satisfaction with family life in female physicians (all $p<.001$ ). A further result is that satisfaction with work does not differ significantly from the representative community sample except of a higher value in male physicians at T5 $(p=.008)$.

Development of life satisfaction in young physicians

Time

As shown in Tables 2 and 3 , the $\mathrm{FLZ}^{\mathrm{M}}$ total score shows an increase from $\mathrm{T} 2$ to $\mathrm{T} 3$, followed by a decrease from $\mathrm{T} 3$ to T4. The satisfaction with leisure activities and friends decline from $\mathrm{T} 1$ to $\mathrm{T} 2$, i.e., in the first year of residency, whereas the satisfaction with income rises in the same time period. The satisfaction with family shows a very instable course: it increases from $\mathrm{T} 2$ to $\mathrm{T} 3$, decreases from $\mathrm{T} 3$ to $\mathrm{T} 4$, and increases again from $\mathrm{T} 4$ to $\mathrm{T} 5$; a similar development is found in satisfaction with partner/relationship. The course of satisfaction with work is stable from $\mathrm{T} 1$ to T5.

\section{Gender}

The only significant difference between men and women is the higher satisfaction with income in women (see Tables 2 and 3, as well as Fig. 1). The importance of income was asked in the former version of the $\mathrm{FLZ}^{\mathrm{M}}$ : In our study, male doctors scored higher $(p<.05)$ at all measurement points.

\section{Gender $\times$ time}

The only significant interaction between the factors gender and time appears in the satisfaction with leisure activities (see Tables 2 and 3, as well as Fig. 1): The values of women decrease more than those of men from $\mathrm{T} 1$ to $\mathrm{T} 2$ and increase from T4 to T5, whereas the values of men decrease in this time period.

Associations between socio-demographic and psychosocial variables and satisfaction with life

The associations between socio-demographic and psychosocial variables on the one hand and satisfaction with life on the other are shown in Table 4. The hierarchical regression analysis shows in the first step that living in partnership plays a significant role for a higher total life

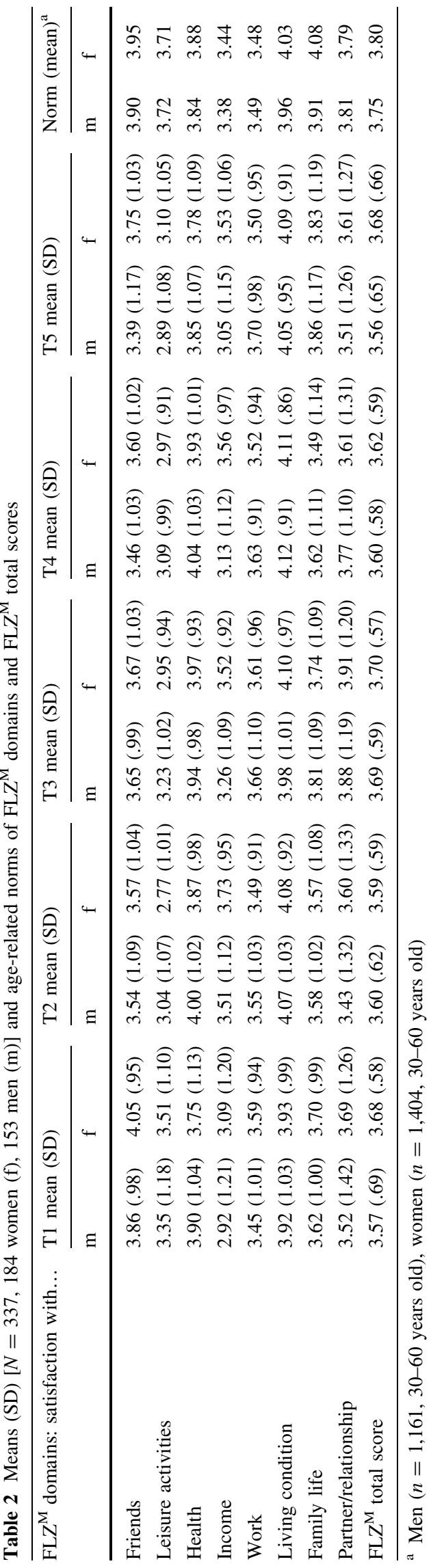


Table 3 Results of multivariate and univariate analyses of variance of FLZ ${ }^{\mathrm{M}}$ domains and FLZ ${ }^{\mathrm{M}}$ total score $(N=337)$

\begin{tabular}{|c|c|c|c|c|c|c|c|c|c|}
\hline \multirow[t]{2}{*}{ FLZ $^{\mathrm{M}}$ domains: multivariate ${ }^{\mathrm{a}}$} & \multicolumn{3}{|l|}{ Gender } & \multicolumn{3}{|l|}{ Time } & \multicolumn{3}{|c|}{ Gender $\mathrm{x}$ time } \\
\hline & $F(8,328)$ & $p$ & Partial $\eta^{2}$ & $F(32,304)$ & $p$ & Partial $\eta^{2}$ & $F(32,304)$ & $p$ & Partial $\eta^{2}$ \\
\hline & 4.71 & $<.001$ & .10 & 6.94 & $<.001$ & .42 & 1.91 & .003 & .17 \\
\hline \multirow[t]{2}{*}{ FLZ $^{\mathrm{M}}$ domains: univariate } & \multicolumn{3}{|l|}{ Gender } & \multicolumn{3}{|l|}{ Time } & \multicolumn{3}{|c|}{ Gender $\times$ time } \\
\hline & $F(1,335)$ & $p$ & Partial $\eta^{2}$ & $F(4,1,340)$ & $p$ & Partial $\eta^{2}$ & $F(4,1,340)$ & $p$ & $\overline{\text { Partial } \eta^{2}}$ \\
\hline Friends & 3.81 & .052 & .011 & 14.41 & $<.001$ & .041 & 2.15 & .076 & .006 \\
\hline Leisure activities & .71 & .399 & .002 & 17.11 & $<.001$ & .049 & 5.81 & $<.001$ & .017 \\
\hline Health & 1.20 & .273 & .004 & 3.19 & .014 & .009 & 62 & .649 & .002 \\
\hline Income & 14.28 & $<.001$ & .041 & 20.97 & $<.001$ & .059 & 2.01 & .102 & .006 \\
\hline Work & .73 & .395 & .002 & 1.21 & .305 & .004 & 1.73 & .147 & .005 \\
\hline Living condition & .30 & .582 & .001 & 2.24 & .066 & .007 & .27 & .889 & .001 \\
\hline Family life & .15 & .703 & $<.001$ & 6.15 & $<.001$ & .018 & .56 & .683 & .002 \\
\hline Partner/relationship & .42 & .518 & .001 & 6.91 & $<.001$ & .020 & 1.35 & .251 & .004 \\
\hline FLZ $^{\mathrm{M}}$ total score & 1.01 & .317 & .003 & 3.10 & .016 & .009 & 1.74 & .142 & .005 \\
\hline
\end{tabular}

${ }^{\text {a }}$ Multivariate statistics are computed without $\mathrm{FLZ}^{\mathrm{M}}$ total score

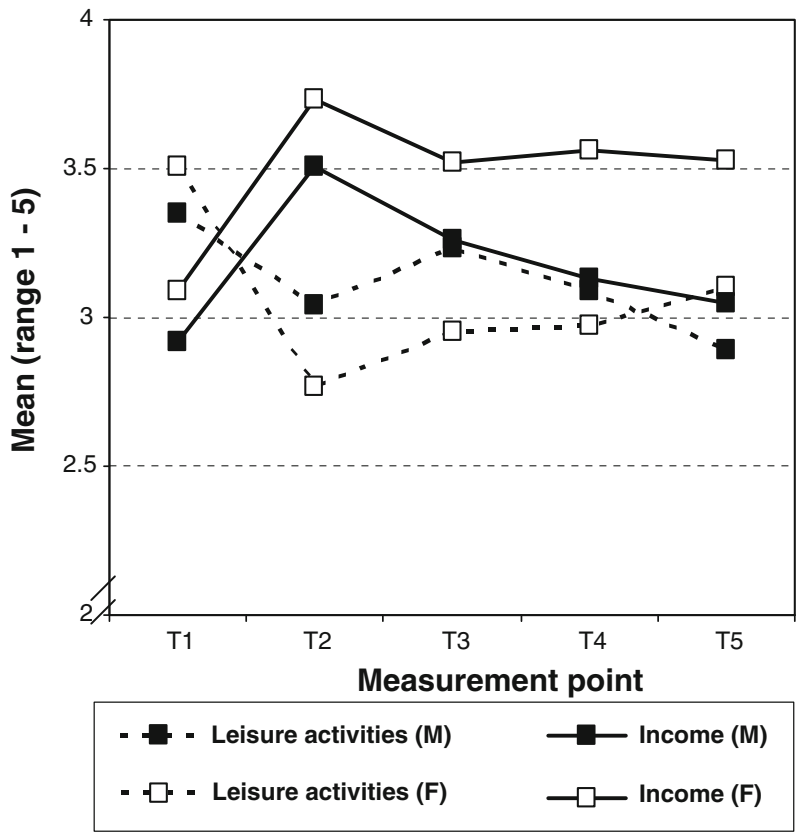

Fig. 1 Gender-related development of the FLZ ${ }^{\mathrm{M}}$ domains 'satisfaction with leisure activities' and 'satisfaction with income' $[N=337$, 184 women $(\mathrm{F}), 153$ men $(\mathrm{M})]$

satisfaction; gender, employment, and own children do not. Controlled for these variables, the second step reveals that depressive symptoms and chronic stress are highly negatively associated with the total life satisfaction. Since $R^{2}$ change is very high, the latter two associations provide a great amount to the total relationship. Anxiety symptoms and sense of coherence have significant associations with life satisfaction in the bivariate analyses, but they are highly related to depressive symptoms and chronic stress.
Therefore, their contribution ( $\beta$-weights) to the amount of the total relationship (adjusted $R^{2}$ ) diminishes in the multiple regression.

\section{Discussion}

The present study is an 8-year follow-up survey of a cohort of medical school graduates. The participants assessed their domain-specific satisfaction with life at five measurement points. The findings were compared with an age-matched representative sample. Furthermore, associations between life satisfaction and person- and health-related factors, respectively, were investigated.

\section{Reliability of FLZ ${ }^{\mathrm{M}}$}

The internal consistency of the $F L Z^{M}$ in our study is satisfactory at each measurement. The values are slightly below those reported by Daig et al. (2009). This can be explained by the homogeneity of our study sample in terms of age and profession. The retest-reliability cannot be compared with other studies. As far as we know, there are no other papers reporting life satisfaction in doctors using domain-specific instruments and cover an 8-year time period.

The average correlation among the five measurement points is .50. This correlation is sufficiently, but not exceedingly high. This indicates that the assessment of life satisfaction is influenced by external conditions (i.e., career entry, workplace and socio-economic conditions), as well as by subjective norms (i.e., individual level of life satisfaction). 
Table 4 Associations between "objective" socio-demographic variables and life satisfaction $\left(\mathrm{FLZ}^{\mathrm{M}}\right.$ total score) and "subjective" variables like anxiety and depressive symptoms (HADS), chronic stress (TICS-SSCS), and sense of coherence (SOC) and life satisfaction $\left(\mathrm{FLZ}^{\mathrm{M}}\right.$ total score), demographic variables $(N=337)$ (hierarchical regression analysis) controlled for socio-

\begin{tabular}{lllr}
\hline & \multicolumn{2}{l}{ Life satisfaction $\left(\mathrm{FLZ}^{\mathrm{M}}\right.$ total score) } & \\
\cline { 2 - 3 } & \multicolumn{1}{l}{$\beta(\mathrm{SE})$} & $t$ & $p$ \\
\hline "Objective" variables & & & .183 \\
Gender (f) & $.08(.06)$ & 1.33 & .001 \\
Living in partnership (yes) & $.18(.06)$ & 3.21 & .467 \\
Having own children (yes) & $.05(.07)$ & .73 & .291 \\
Employment in percent & $-.07(.07)$ & -1.06 & $<.001$ \\
& Adjusted $R^{2}=.05$ & $F(4,328)=5.17$ & .746 \\
"Subjective" variables & & & $<.001$ \\
Anxiety symptoms & $-.02(.07)$ & -.33 & $<.001$ \\
Depressive symptoms & $-.44(.06)$ & -7.90 & .133 \\
Chronic stress & $-.25(.06)$ & -4.14 & $<.001$ \\
Sense of coherence & $.07(.05)$ & 1.51 & $<.001$ \\
& Adjusted $R^{2}=.50$ & $F(8,324)=41.34$ & \\
& $R^{2}$ change $=.45$ & Change in $F=72.96$ & \\
\hline
\end{tabular}

Development of life satisfaction over time

Life satisfaction in young physicians compared with an age-matched representative community sample

As most psychologic tests, the FLZ ${ }^{\mathrm{M}}$ has no validation particular for the German-speaking part of Switzerland. Usually, the German reference group is consulted for comparisons because this group is most comparable regarding language, cultural background, and environment. All FLZ ${ }^{\mathrm{M}}$ total scores are below the values of the age-matched representative community sample. This result is mainly caused by the low satisfaction with leisure activities. Similar results are reported by other authors who also found lower levels of life satisfaction in physicians in the postgraduate years (Tyssen et al. 2009). These findings can be partly explained by physicians' general high workload especially during residency. However, another Norwegian study (Nylenna et al. 2005) shows a high level of general life satisfaction in a representative sample of 1,174 Norwegian doctors-and even an increase of life satisfaction in this sample within the time frame from 1994 to 2002. Restrictively, this sample includes doctors of all ages. In a Norwegian prospective study (Kjeldstadli et al. 2006), a decrease in life satisfaction during medical school is reported. Both samples cannot be compared with our study sample.

A further result in our study is the lower satisfaction with family life in women compared to the representative community sample. Most probably, several factors play a role: in the Swiss society, women still feel more responsible for family concerns as men (Maume 2006); another point is a lack of sufficient child care facilities in Switzerland compared to other countries as France or Scandinavia.

As other authors do not report domain-specific results (Kjeldstadli et al. 2006; Tyssen et al. 2009), we cannot compare our findings to other studies.
The domain-specific values show a significant decrease in leisure activities and friends from $\mathrm{T} 1$ to $\mathrm{T} 2$ and an increase in income in the same time period. The latter finding is not surprising, considering that respondents have just graduated from medical school at $\mathrm{T} 1$ and earning their first money in residency at $\mathrm{T} 2$.

Overall, our results show the highest life satisfaction at T3. Several factors may play a role: First, in this phase of residency, young doctors have achieved a certain level of confidence by professional experience; second, the participants are meanwhile in a phase of life in which most of them live in a relatively stable personal situation providing emotional and social support. That does not exclude that the satisfaction with partnership and family underlies a certain variability over time, as shown in our data.

Job satisfaction is stable over the whole 8-year time period. As reported in other studies (Buddeberg-Fischer et al. 2006, 2008c; Deberdt 2002), the younger generation attach more importance to leisure activities, friends, and family than the older generation. In addition, the attitude of young physicians toward the medical profession can be characterized as "my job is my life" (Armstrong et al. 2009).

Gender-specific differences are only found in the domain 'satisfaction with income': women are more satisfied than men, although they earn the same salary which is regulated by the government. We assume that the socioeconomic status is more important for men than for women. Using the former version of the FLZ ${ }^{\mathrm{M}}$ (Henrich and Herschbach 2000), the 'importance of income' as an indicator for the socio-economic status was assessed: at all measurement points, male doctors scored higher. Thus, our assumption is confirmed. Furthermore, men compare their 
income more often with others, as shown in a meta-analysis (Pinquart and Sörensen 2000).

A significant interaction between gender and time is found in the domain leisure activities: women show a greater decrease from $\mathrm{T} 1$ to $\mathrm{T} 2$ than men. As known, cultivating friendships is an essential issue for women (Sherman and Walls 1995). The career entry and therewith high workload does not leave them enough time for their social network. The interaction is also significant from $\mathrm{T} 4$ to T5: men assess a decrease in leisure activities, and women show an increase. It can be supposed that at the end of residency, male doctors invest more time in their professional career entailing less leisure activities (BuddebergFischer et al. 2008d).

In the course of the FLZ ${ }^{\mathrm{M}}$ total score, it has to be considered that this score is a sum score over the domains. Opposed courses in the various domains at different measurement points might outweigh one another by summarizing the values. For example: from $\mathrm{T} 1$ to $\mathrm{T} 2$, the satisfaction with income increases, whereas satisfaction with leisure activities decreases, no change in the total score.

Associations between socio-demographic and psychosocial variables and satisfaction with life

As regards objective socio-demographic variables, living in stable partnership is strongly associated with life satisfaction. Partnership has been consistently reported to be related to better life satisfaction, providing emotional and social support (Daig et al. 2009; Jurkat and Reimer 2001; Rockenbauch et al. 2006; Tyssen et al. 2009). Age was not included in the analysis because of the homogeneity of the participants.

Additionally, depressive symptoms and chronic stress are found to diminish life satisfaction, findings also reported by other authors (Daig et al. 2009; Saarni et al. 2007).

Limitations of our study: Participants are a rather homogeneous sample in terms of age and professional status and are not a representative community sample. Over time, only half of the cohort study sample delivered complete data sets. This is almost inevitable in cohort studies tracking individuals over 8 years. However, there are no significant differences between dropouts and participants regarding gender, age, and life satisfaction at $\mathrm{T} 1$.

The major strengths of this study are the long follow-up period over 8 years with five assessments and the comparison with an age-matched representative community sample. Furthermore, we have used several validated instruments to ensure high reliability of the reported data. In particular, we applied a domain-specific life satisfaction questionnaire. In several studies on life satisfaction in physicians, only a one-item question is used (Kjeldstadli et al. 2006; Nylenna et al. 2005; Tyssen et al. 2009).

\section{Conclusions}

To study the development of life satisfaction over time, it is more appropriate to use specific domains of life satisfaction than a total score. Furthermore, it is a matter of concern that-compared to a representative sample-physicians show lower life satisfaction not only at the beginning of their professional life but also 8 years later, when it could be assumed that at this time, they have adapted to the demands of their profession. Depressive symptoms and chronic stress are found to diminish life satisfaction. This could keep some physicians from staying in the medical profession. Senior physicians should be aware of the negative impact of chronic stress on life satisfaction.

Acknowledgments The study was supported by grants from the Swiss National Science Foundation (NF Nos. 3200-061906.00, 3200 BO-102130, 3200 BO-113836).

Conflict of interest statement The authors declare that they have no conflict of interest.

\section{References}

Antonovsky A (1987) Unraveling the mystery of health. How people manage stress and stay well. Jossey-Bass, San Francisco

Armstrong A, Alvero R, Dunlow S, Nace M, Baker V, Stewart E (2009) Balancing the professional and personal. Fertil Steril 91:18-21

Buddeberg-Fischer B, Dietz C, Klaghofer R, Buddeberg C (2006) Swiss residents' arguments for and against a career in medicine. BMC Health Serv Res 6:98

Buddeberg-Fischer B, Klaghofer R, Abel T, Buddeberg C (2003) The influence of gender and personality traits on the career planning of medical students. Swiss Med Wkly 133:535-540

Buddeberg-Fischer B, Klaghofer R, Buddeberg C (2005) Arbeitsstress und gesundheitliches Wohlbefinden junger Ärztinnen und Ärzte. Z Psychosom Med Psyc 51:163-178

Buddeberg-Fischer B, Klaghofer R, Stamm M, Siegrist J, Buddeberg $\mathrm{C}$ (2008a) Work stress and reduced health in young physicians: prospective evidence from Swiss residents. Int Arch Occup Environ Health. doi: 10.1007/s00420-008-0303-7

Buddeberg-Fischer B, Stamm M, Buddeberg C, Bauer G, Haemmig O, Klaghofer R (2008b) Arbeitsstress, Gesundheit und Lebenszufriedenheit junger Ärztinnen und Ärzte. Ergebnisse einer Schweizer Longitudinalstudie. Deut Med Wochenschr 133:2441-2447

Buddeberg-Fischer B, Stamm M, Buddeberg C, Bauer G, Hämmig O, Knecht M, Klaghofer R (2010) The impact of gender and parenthood on physicians' careers-professional and personal situation seven years after graduation. BMC Health Serv Res 10:40

Buddeberg-Fischer B, Stamm M, Buddeberg C, Klaghofer R (2008c) The new generation of family physicians - career motivation, life goals and work-life balance. Swiss Med Wkly 138:305-312 
Buddeberg-Fischer B, Stamm M, Buddeberg C, Klaghofer R (2008d) Career-Success Scale-a new instrument to assess young physicians' academic career steps. BMC Health Serv Res 8:120

Daig I, Herschbach P, Lehmann A, Knoll N, Decker O (2009) Gender and age differences in domain-specific life satisfaction and the impact of depressive and anxiety symptoms: a general population survey from Germany. Qual Life Res 18:669-678

Deberdt JP (2002) Employment, a declining value. Presse Med 31:488-490

Edwards N, Kornacki MJ, Silversin J (2002) Unhappy doctors: what are the causes and what can be done? Brit Med J 324:835-838

Goldbeck L, Schmitz TG (2001) Comparison of three generic questionnaires measuring quality of life in adolescents and adults with cystic fibrosis: the 36 -item short form health survey, the quality of life profile for chronic diseases, and the questions on life satisfaction. Qual Life Res 10:23-36

Henrich G, Herschbach P (2000) Questions on Life Satisfaction (FLZ). A short questionnaire for assessing subjective quality of life. Eur J Psychol Assess 16:150-159

Herrmann C, Buss U, Snaith RP (1995) Hospital Anxiety and Depression Scale-Deutsche Version. Ein Fragebogen zur Erfassung von Angst und Depressivität in der somatischen Medizin. Testdokumentation und Handanweisung. Huber, Bern. Göttingen, Toronto

Hinz A, Schwarz R (2001) Angst und Depression in der Allgemeinbevölkerung. Eine Normierungsstudie zur hospital anxiety and depression scale. Psychother Psychosom Med Psychol $51: 193-200$

Jurkat HB (2008) Lebensqualität bei Ärztinnen und Ärzten. Erfahrungen aus der empirischen Forschung. Dtsch Med Wochenschr 133:14-16

Jurkat HB, Reimer C (2001) Lebensqualität und Gesundheitsverhalten von berufstätigen Ärztinnen im Vergleich zu Ärzten. Schweizerische Ärztezeitung 82:1739-1744

Kjeldstadli K, Tyssen R, Finset A, Hem E, Gude T, Gronvold N et al (2006) Life satisfaction and resilience in medical school-a six year longitudinal, nationwide and comparative study. BMC Med Educ 6:48

Maume D (2006) Gender differences in restricting work efforts because of family responsibilities. J Marriage Fam 68:859-869
Nylenna M, Gulbrandsen P, Foerde R, Aasland OG (2005) Unhappy doctors? A longitudinal study of life and job satisfaction among Norwegian doctors 1994-2002. BMC Health Serv Res 5:44

Pinquart M, Sörensen S (2000) Influences of socioeconomic status, social network, and competence on subjective well-being in later life: a meta-analysis. Psychol Aging 15:187-224

Rockenbauch K, Meister U, Schmutzer G, Alfermann D (2006) Lebenszufriedenheit von AbsolventInnen der Medizin. Eine empirische Untersuchung zum Vergleich der Lebenszufriedenheit von AbsolventInnen mit Gleichaltrigen sowie zur Aufklärung des Faktors Lebenszufriedenheit. (Alumni of medical sciences and their life satisfaction). Gesundheitswesen 68:176184

Saarni SI, Suvisaari J, Sintonen H et al (2007) Impact of psychiatric disorders on health-related quality of life: general population survey. Brit J Psychiat 190:326-332

Schulz P, Scholtz W, Becker P (2004) Trier Inventory for the Assessment of Chronic Stress (in German). Hofgrefe, Goettingen

Schumacher J, Klaiberg A, Brähler E (2003) Diagnostik der Lebensqualität und Wohlbefinden - Eine Einführung. In: Schumacher J, Brähler E (eds) Diagnostische Verfahren zu Lebensqualität und Wohlbefinden (Diagnostik in Klinik und Praxis). Hogrefe, Göttingen, pp 9-24

Shanafelt TD, Sloan J, Habermann T (2003) The well-being of physicians. Am J Med 114:513-519

Sherman A, Walls J (1995) Gender differences in the relationship of moderator variables to stress and symptoms. Psychol Health 10:321-331

Tyssen R, Hem E, Gude T, Gronvold NT, Ekeberg O, Vaglum P (2009) Lower life satisfaction in physicians compared with a general population sample: A 10-year longitudinal, nationwide study of course and predictors. Soc Psychiatry Psychiatr Epidemiol 44:47-54

Williams E, Rondeau K, Xiao Q, Francescutti L (2007) Heavy physician workloads: impact on physician attitudes and outcomes. Health Serv Manage Res 20:261-269

Williams ES, Manwell L, Konrad T, Linzer M (2007) The relationship of organizational culture, stress, satisfaction, and burnout with physician-reported error and suboptimal patient care: results from the MEMO study. Health Care Manage Rev 32:203-212 